\title{
On Modelling Migrant Behavior Driven by Imitation
}

\author{
Elvio Accinelli ${ }^{1}$, Edgar J. Sánchez Carrera ${ }^{1, *}$ and Osvaldo Salas ${ }^{2}$
}

${ }^{1}$ Facultad de Economía, UASLP, México

${ }^{2}$ School of Public Administration, University of Gothenburg, Sweden

\begin{abstract}
This paper studies the evolutionary dynamics of migration. We argue that, under bounded rationality, the strategic foundations of the migrant behavior are based in the imitation of peers. We show that any migratory flow can be modeled from a dynamical system, whose parameters reflect the social and economic policies implemented by the decision maker and the rules of the imitative process followed by the population. Education or technological innovation subsidies can lead to an increasing flow of skilled workers to the country in which this policy is more intensively developed. Impact of such subsidies on migration processes can be easily analyzed based on our model. We show that an economy may avoid skilled workers losses as a result of migration flows, only if the number of local firms investing in research and development exceeds a certain threshold value. Moreover, if this value is exceeded, such an economy is attending a positive process of imitation of skilled workers.
\end{abstract}

Keywords: Migrant behavior, Imitation theory, Replicator dynamics, Social welfare.

\section{INTRODUCTION}

HHarris-Todaro (1970) pointed out that disparity of wages is the main driving force encouraging migration processes (see also, Todaro, 1969; Langley, 1974; Hart, 1975; Borjas, 1990, 1994). This point of view has been complemented by the introduction of other facts that impact on this phenomenon, as risk aversion, priority hiring, preferences, travel costs, familiar affects etc, and it be can certainly extended to analyze migratory processes between countries. Wage gap between the host and the home country is considered the main variable affecting migration decision. Evidence seems to stress on the focal role of community networks in the migrant's choice, see for instance, Boyd, (1989); Bauer and Zimmermann, (1997); Bauer et al., (2002); Coniglio, (2003); Munshi, (2001), (2003); Heitmueller, (2003); Winters et al., (2001). Moretti (1999), for example, with an alternative model to Todaro's, found evidence that both the timing and the destination of migration could be explained by the presence of social networks in the host country. However, Borjas (1994) concluded that the literature so far failed to provide enough understanding of how immigrants inflows affect native workers in the host country labor market. In his paper, he presents several examples in which both native wages and employment were not affected by a significant inflow of immigrants. The main contribution of this paper is to employ Evolutionary Game Theory to explain migration. We contemplate the role of the imitation in the processes of

*Address correspondence to this author at the Facultad de Economía de la UASLP (Mexico), Av. Pintores S/N. Fraccionamiento Burócratas del Estado, CP 78263, San Luis Potosí SLP, México; Tel: +52 4448131238 ext 120;

E-mail: edgar.carrera@uaslp.mx

JEL Classification: C72, F22, O3, R1. migration between countries, considering imitation as a natural mechanism to make decisions. We follow the model considered in Accinelli, E. and Carrera, E.S. (2011). Many scholars argue that individuals under bounded rationality follow heuristics methods to make decisions. These streams of research argue that, in order to make decisions under bounded rationality, heuristics are faster, more frugal and more accurate, than other complex and sophisticated methods.

In general, we can say that heuristic is a strategy that ignores part of the information, a shortcut that simplify complex methods of calculating probabilities and utilities required to make decisions under uncertainty. Taking this definition into account, imitation is an heuristic method, which may explain why imitation-based choice may be an effective strategy under certain circumstances. For a detailed explanation of the heuristics methods, see for instance [Gigerenzer, G.; Gaissmaier, W. (2011)], [Gigerenzer, G.; Goldstein, D.G (2011)]. To our best knowledge, such a framework to explain migration processes, has not been developed yet. Evolutionary game theory has been used to study many other problems such as the evolution of crime over time [Cressman, Morrison and Wen (1998)], the banking system and corporate governance in the case of post-socialist Lithuania [Marmefelt (2004)] and the effect of economic agents behaviour on the long-run performance of the economy [Carrera (2009)]. Marmefelt (2004) includes own population effects in the replicator equations. Many other applications of Evolutionary Games Theory to social problems can be found in Friedman (1998). In this paper, we consider that economic agents often takes as reference the behavior of their neighbors, peers or those who believe more successfully given the 
current state of the economy. This imitation process, whose rules can be reflected in a dynamical system, such that its solutions show the possible evolution of each particular migratory process. It has long been recognized that an individual's behavior might be influenced by their peers and by the environmental conditions in which he is immersed. Peers, may affect behavior and hence market outcomes, several economic studies of peer effects have recently emerged in a variety of domains. Examples include education (Graham, 2008), crime (Glaeser, Sacerdote and Scheinkman, 1996), unemployment insurance take-up (Kroft, 2008), welfare participation Bertrand, Luttmer and Mullainathan, 2000), and retirement planning (Duflo and Saez, 2003). Then, peer effect is found in many social and economic behaviors (see Durlauf (2004) for an exhaustive literature survey).

The rest of this work is organized as follows. In section we consider an empirical introduction. Section 3 introduces the model as a two-stage game about the decision to migrate or not depending on expected payoffs. Section 4 develops the worker's population game and the mean dynamic of migration. Section 4.1. develops the dynamics of the imitation process and shows the main results of the paper. Section 5 concludes the paper.

\section{SOME EMPIRICAL CONSIDERATIONS}

An empirical example is the Swedish experience, since the mid-eighteenth century to the 1930 mass migration to the United States. In the US in 1891 began a process of industrialization which leads many of these migrants to become specialized workers, this process is the result of a process of imitation that arises among the Swedish population established in this country, process based on a real growth of the probability of getting better wages as skilled industrial workers. See for instance Ljungmark (1992). The combination of push factors in Europe and pull factors in the United States explains the causes of European migration, Ljungmark (1979). The push factors that characterize the Swedish emigration are: i) overpopulation resulted from improved health, better food and a prolonged period of peace, ii) religious intolerance of the time contrasted with religious freedom offered by the new land iii) social class differences, and iv) migration offering out of poverty and unemployment among large social Ljungmark, (1992). All of these are social factors that are involved in the development of individual preferences for migration. Table 1 shows that a total of $1,122,292$
Swedes immigrated to the United States during the period $1851-1930$.

Added to this is estimated at about 100000 people emigrated population not recorded by official statistics, and nearly 200000 people have returned to Sweden before 1930. Therefore, the Swedish population decreases during the period mentioned in more than one million people, Carlsson (1976). To give perspective to these figures, in 1930 Sweden's population was $6,142,191$ people (SCB, 1969), that is, to date almost one fifth of the population had emigrated ${ }^{1}$.

Table 1: Registered Emigration from Sweden to America, 1851-1930

\begin{tabular}{|c|c|}
\hline Period & emigrants \\
\hline \hline $1851-1860^{*}$ & 14.865 \\
\hline $1861-1870$ & 88.731 \\
\hline $1871-1880$ & 101.169 \\
\hline $1881-1890$ & 324.285 \\
\hline $1891-1900$ & 200.524 \\
\hline $1901-1910$ & 219.249 \\
\hline $1911-1920$ & 81.537 \\
\hline $1921-1930$ & 91.932 \\
\hline Total & $1,122.292$ \\
\hline
\end{tabular}

The first wave of massive emigration was composed mainly by small farmers and agricultural workers who left behind small holdings and farms. At this time, the United States offered the opportunity to acquire a large amount of surface to very reasonable price. This fact reaffirms the assumption of no change between types in the population of emigrant workers, i.e. migrant farmers will remain as such in the new land. The low cost of settling in the new lands, the major benefits expected and the few existing opportunities for these workers in their own land, make that the decision to migrate is widespread in this sector of the Swedish population, despite the limited information available about the likelihood of achieving the chosen destination. The frequency of migrants from the upper classes was significantly lower compared to low-income sectors, Carlsson (1976). No doubt that for the upper class migration had a high opportunity cost

${ }^{1}$ Source: Carlsson, Sten (1979). * Period 1851-1880 includes people who have emigrated to Canada. 
thus providing a low probability of improving the level of income earned in the local labor market. Regarding the migration decision-making is interesting to note two observations. First, the Swedish emigrant took his decision to emigrate despite the lack of information. Second this decision is carried on only by individuals of a distinct segment of the population. Both observations point in the sense that peer imitation plays an important role in the process of decision making under bounded rationality. Clearly in this case a heuristic method, replaces a more complicated calculation of probabilities of success an utilities that would not do more than delay a decision that cannot wait. After 1910 the number of Swedish workers willing to emigrate decreases faster, basically, because most of them already did so, and/or because the expansion and conquest of the American West was finished, meaning, among other things, that reducing the supply of land at low prices, and on the other hand, the accelerated process of industrialization in the United States, begins to require fundamentally skilled workers. Meanwhile, Sweden attends a process of industrialization of the economy, although it is not as fast as the U.S., begins to require also, skilled workers. In response to this need, the Swedish government implemented a set of measures to train potential workers for new industries. After some time, the probability that an unskilled worker decide to become skilled exceeds the probability that decide to emigrate. Consequently, the probability that firms find in the labor market skilled workers, increases. Thus, the potential profits of innovative firms increases, and also begins in this country, a cycle of increasing industrialization. It is important to remark that Swedish government played an important role in this process by encouraging, through support to education and subsidies to innovative firms.

The example of Australia in the recent years, shows a interested government in encourage migration to their country of highly skilled workers. Today this country is an example of an attractor for skilled migrant workers. This is because, with the intention of boosting the Australian economy, in particular the development of high-technology enterprises, the Government has created 108,000 new jobs for English speaking professionals with labor skills in different occupations. See the web page of the Australian Government, Department of Inmigration and Border Protection. Although the information does not arrive equally to all developing countries, we are witnessing of a growing migratory flow from these countries to Australia. We argue that this process is encouraged by imitation of the peers.

\section{THE MODEL}

Consider an economy conformed by two countries denoted by $\mathrm{A}$ and $\mathrm{B}$, each one with two types of firms, innovative I and non-innovative $\mathrm{NI}$, and two types of workers skilled $s$ and unskilled us. We assume that there is not unemployment nor among residents nor among migrants, but some of them can be employed in jobs requiring fewer or higher skills. In addition we consider that:

1. Total number of firms in each country is given. However, firms can choose between be innovative or not, so the distribution of these two types can change over time. Economies are in equilibrium, so the production plans of firms are optimal, however this does not mean that profits of firms in different branches or using different technologies are the same. So, in order to obtain greater benefits, after the equilibrium prices are know, owners may decide to invest in other branches or to change the production technology used at present.

2. There are strategic complementarities. That is, the profits of innovative firms employing a skilled worker is greater than the profit when employing a unskilled worker, i.e: $\pi^{j}(I, s)<\pi^{j}(I, u s)$ Also, the profits of non-innovative firms employing skilled workers is lower than the profits employing unskilled workers, i.e: $\pi^{j}(N I, s)<\pi^{j}(N I, u s), j \in\{A, B\}$. Note that overqualified workers tend to hinder the normal development of the production process. In particular skilled workers are often poorly motivated when routine tasks are imposed.

3. In both countries $A$ and $B$, non-innovative firms pay the same wages, this wage is denoted by $Y_{(N I, s)}^{j}=Y_{(N I, u s)}^{j}=Y_{(u s)}^{j}>0$. While innovative firms pay higher wages to skilled workers, i.e. $Y_{(I, s)}^{j}>Y_{(I, u s)}^{j}=Y_{(N I, u s)}^{j}=Y_{(N I, s)}^{j}, \forall j \in\{A, B\}$.

4. To remain or become skilled worker there is a fixed training cost denoted by $c_{s}^{j}>0$, in each country $j \in\{A, B\}$. We assume that knowledge depreciates, so we consider skilled those workers whose knowledge evolves with the technology. Keep up involves perform permanent training courses, which certainly has an associated cost.

5. When a skilled worker from country $A$ decides to migrates to country $B$, she may be engaged by a 
non-innovative firm or by an innovative firm. Then, the expected earning of a skilled worker in time $t$ in a given country is:

$E_{s}^{j}(t)=p_{I}^{j}(t) Y_{(I, s)}^{j}(t)+p_{N I}^{j}(t) Y_{(N I, s)}^{j}(t)-c_{s}^{j}(t), \forall j \in\{A, B\}$.

where $p_{I}^{j}$ is the probability to be engaged by innovative firm, and $p_{N I}^{j}$ by a non-innovative firm in the $j$-country. Since we assume full employment, then $p_{I}^{j}+p_{N I}^{j}=1$ and more specifically these probabilities are equal to the share of innovative and non-innovative firms in the country $j$. The expected earning of a unskilled worker from country $j \in\{A, B\}$ is given by:

$E_{u s}^{j}=Y_{I, u s}^{j}(t)=Y_{(N I, u s)}^{j}(t)=Y_{(u s)}^{j}(t)$.

6. On the other hand, skilled and unskilled workers can choose between migrate or do not migrate. We assume that if a skilled (unskilled) worker chooses to migrate, then she remains as a skilled (unskilled) worker in the foreign country.

Wages and profits, in each country, are summarized in the following payoff matrix, where to simplify the notation we omit the variable $t$ :

$$
\begin{array}{ccc}
\frac{\text { Firm }}{\text { Worker }} & I & N I \\
s & Y^{j}(s, I), \pi^{j}(I, s) & Y^{j}(u s, N I), \pi^{j}(I, s) \\
u s & Y^{j}(u s, I), \pi^{j}(I, u s) & Y^{j}(u s, N I), \pi^{j}(N I, u s)
\end{array}
$$

This one shot game is played in a continuous time. In each period there are two Nash equilibria, in pure strategies, $\{s, I\}$ and $\{u s, N I\}$, both are the result of the existence of strategic complementarity (already mentioned as a characteristic of this game, above in item (2)), and a mixed strategy Nash equilibrium where a pure strategy is chosen at random, subject to some fixed probability that depend on the share of innovative and non-innovative firms and the share of skilled and unskilled workers.

Remark 1. If workers and/or firms know the expected value associated with each available strategy or behavior, then the choice for being skilled or unskilled in each country depends of:

i) the differential of wages,

ii) the share of innovative firms, and

iii) the training costs or education costs. The decision of the firms about being innovative or not, depends on the probability to hire skilled workers.
Preferences play an important role in determining behavior. If they have preferences for migration, then the individual's decision to migrate from country A (home) to country B (foreign country) depends on two main variables: i) the expected income differences between countries, and ii) the migration costs. Then, for skilled workers, the preference-value of migration is given by:

$V_{s}\left(t_{0}\right)=\int_{t_{o}}^{t_{f}}\left[E_{s}^{B}(t)-E_{s}^{A}(t)\right] e^{-r t} d t-C_{B A}(0)$

where $V_{s}\left(t_{0}\right)$ is the discounted present value of the net gain from migration. By $r$ we represent the discount rate on future profits. Although this is unique for each individual, we assume for simplicity, that it is constant and equal to $r$ for each. The interval $\left[t_{0}, t_{f}\right]$ is the planning horizon, $C_{A B}(0)>0$ denotes the cost to emigrate from country $A$ to country $B$. In the case when, $V_{s}(0)$, is positive, then (rational) potential migrant will decide to move from country $A$ to country $B$, otherwise she does not migrate.

Analogously for unskilled worker:

$V_{u s}\left(t_{0}\right)=\int_{t_{o}}^{t_{f}}\left[Y_{u s}^{B}(t)-Y_{u s}^{A}(t)\right] e^{-r t} d t-C_{B A}(0)$,

and the decision to migrate is according with the sign of the discounted present value of the net gain from migration.

Remark 2. Therefore, a worker decides to migrate when her/his discounted present value, $V(\cdot)$, is positive, otherwise he/she stays in their home country.

Let us study the evolutionary dynamics of migration, when preferences to migrate, which define the discounted present value of migration are driven by imitation.

\section{ON THE EVOLUTIONARY DYNAMICS OF MIGRATION}

Consider that in every period of time $t$ the reviewer workers, $s$ and $n s$, choose either to remain as their original type, $s$ and $n s$, in their original country, A or $\mathrm{B}$, or they can choose to change their type in their original country. So we consider that the probability to change types and migrate at the same time is an event of zero probability.

In this section, we derive a deterministic model of evolution: the mean dynamic generated by a population game (see Hofbauer and Sigmund (2003) and Sandholm (2001)). This deterministic evolutionary dynamic is a rule for assigning the population game of 
migration to a ordinary differential equation describing the evolution of behavior in the migration game.

In time $t$ the share of skilled workers in country $j \in\{A, B\}$ is given by $n_{s}^{j}(t)$ and the share of unskilled is by $n_{u s}^{j}(t)$. While the share of innovative firms is given by $p_{i}^{j}(t)$ and the share of non-innovative firms is $p_{n i}^{j}(t)$.

So the workers' distribution in countries is $n=\left(n_{s}^{A}, n_{u s}^{A}, n_{s}^{B}, n_{u s}^{B}\right)$ which is $n_{s}^{A}+n_{u s}^{A}+n_{s}^{B}+n_{u s}^{B}=1$ and $n_{h}^{j} \geq 0$. Assume that the size of the population is constant.

Therefore, the instantaneous change tax on the number of workers following in time $t$ a given strategy strategy is given by the following differential equation system, where with a dot above the variable we indicate the derivative with respect to time

$$
\begin{aligned}
& \frac{\dot{n}_{s}^{j}(t)}{n_{s}^{j}(t)}=\left[E_{s}^{j}(t)-M_{s}^{j}(t)\right] \\
& \frac{\dot{n}_{u s}^{j}(t)}{n_{s}^{j}(t)}=\left[E_{u s}^{j}(t)-M_{u s}^{j}(t)\right]
\end{aligned}
$$

by $E_{h}^{j}(t)$ we denote the expected payoff of a worker of type $h \in\{s, u s\}$ in country $j$ in time $t$, and

$$
M_{h}^{j}(t)=\max \left\{E_{k}^{j}(t), V_{h}^{j}(t)\right\}, h \neq k \in\{s, u s\}
$$

where $V_{h}^{j}(t)$ the expected payoff of migration (see equation (4)) for a worker of type $h$.

Remark 3. So, the share of $s$-workers increases (decreases) if their payoff is larger (smaller) than the maximum payoff corresponding to the other available strategy.

This dynamic is valid only under complete information, i.e.; only if workers know the true distribution of the firms over its types and the cost associated with migration. However, such values are generally unknown by workers. Hereafter, we propose an alternative mechanism, namely an imitation process. Each worker under incomplete information imitates their peers on a social network, and takes his/her decision. ${ }^{2}$

\footnotetext{
${ }^{2}$ Behavioral rules driven by imitation have a long tradition in the literature of evolutionary game theory. One of the best known evolutionary models, the replicator dynamics, describes an evolutionary process which is driven purely by imitation of other as (see Weibull, 1995).
}

\subsection{The Workers' Imitative Behavior}

We argue that preferences for migration are transmitted by imitation. This idea complements the usual approach that attributes migration to economic variables such as wage differentials and risk aversion, since we include imitative behavior like a social phenomena. Imitation appears as an habitual option when decision must be doing under bounded rationality or when there is not time to process all the information required to solve a choice problem. See for instance [5]. Imitation is a strategy that ignores part of information, is a shortcuts that simplify the complex method of calculating probabilities and expected profits that are required to make decisions under uncertainty. In some cases its leads to better decisions than more complex models, (at least for a short period). Several recent empirical studies show that, methods like imitation, can be successful in the absence of complete information, or when the time required to make decisions is very short and it is not possible to process all the required information to solve the decision problem, in the required time. Imitation can be a valid mechanism to decide, when delay is not an option. See for instance, [18] and [?].

Each economic agent (in our model, firm or worker) proceed according to the information available at the time of choosing, if this is incomplete they need a complementary mechanism that allows to make this choice. But, independently of this, given the lack of information, the choice will not necessarily be the best. We understand that imitate, the behavior of those who are considered as leaders, or the behavior of the majority, are natural and useful criteria for choosing the future strategy when the available information is incomplete. Or when there is not enough time, to process all the information required to ensure the best choice. All variants of this type of behavior can be called imitative.

By understanding the rules that govern this behavior, it is possible to describe the economy as an evolutionary process based on a dynamical system, whose solution, depending on the initial conditions, show the state of the economy at any particular moment, and its future evolution. Let us now consider some of the main features of an imitative process of peers. Immediately after, we will build the dynamic system ruling the evolution of the migratory process.

1. Recall that to become or to remain as a skilled worker has an associated cost of education (or 
training cost) $c_{s}^{j}(t)>0$. This cost depends on the country $j \in\{A, B\}$. If, at the end of a period, a worker does not pay this cost, then he becomes unskilled for the next period.

2. A worker in period $t$ is a reviewer when either he/she makes to himself the question about to remain or to change his/her current type, or if to choose to emigrate or not.

3. We consider that a worker becomes a reviewer with probability, $w_{h}^{j}(t) \in[0,1]$ depending on the type $h \in\{s, u s\}$ and country $j \in\{A, B\}$.

4. After being a reviewer, a worker $h$ changes his/her type to $k$, where $h \neq k \in\{s, u s\}$, with probability $\rho^{j}(k / h)(t) \in[0,1]$.

5. So, the probability that a worker of type $k$ imitates a worker of type $h$ in country $j$ is given by:

$P^{j}(k \rightarrow h)(t)=w_{k}^{j}(t) \rho^{j}(h / k)(t)$.

6. Analogously the probability that a worker of type $h \in\{s, u s\}$ from country $i \in\{A, B\}$ decides to migrate to country $j$ is given by:

$P_{h}(i \rightarrow j)(t)=w_{h}^{i}(t) \rho_{h}(j / i)(t) \in[0,1]$,

where $\rho_{h}(j / i)(t)$ is the probability that a reviewer worker of type $h$ and country $i$ migrates to country $j$.

In that follows, in order to to simplify the notation, if there is no risk of confusion, we avoid the uses of the variable $t$. The following proposition summarizes the possible results about evolutionary model of migration

Proposition 1 The evolutionary dynamics of migration driven by imitation is given by:

$\dot{n}_{h}^{j}=\left[n_{k}^{j} w_{k}^{j} \rho^{j}(h / k)-n_{h}^{j} w_{h}^{j} \rho^{j}(k / h)\right]$

$+\left[n_{h}^{i} w_{h}^{k} \rho^{h}(j / i)-n_{h}^{j} w_{h}^{j} \rho^{h}(i / j)\right]$

$j \neq i \in\{A, B\}$, and $h \neq k \in\{s, u s\}$

and looking the behavior of their peers, each worker is able to construct a preliminary draft of the prevailing wages in foreign countries and chances of being employed by types of firms, and so if the expected payoffs of skilled workers in home country is larger than the corresponding expected payoff in foreign country, then the flux of these kind of workers is equal to zero, that is no migration of skilled workers. Otherwise when expected payoffs of skilled workers are higher in foreign country, there will be migration of skilled workers and home country will be in a poverty trap.

Proof. The probability that a worker changes his/her type from $h$ to $k$ or migrates from country $j$ to country $i$, is given by: $w_{h}^{j}\left[p^{j}(h / k)+\rho^{h}(j / i)\right]$, where $p^{j}(h / k)$ is the probability of changing type and $\rho_{h} h(j / i)$ is the probability of migration. Consider that $w_{h}^{j}\left[p^{j}(h / k)\right.$ is the time to arrive of a Poisson Process, where the decision to change or not of each individual are independent and identically distributed random variables. Then, the aggregate increases of the percentage of individual following the strategy $h i$ country $j$ is:

$$
\begin{aligned}
& {\left[n_{k}^{j} w_{k}^{j} p^{j}(h / k)-n_{h}^{j} w_{h}^{j} \rho^{j}(k / h)\right]+\left[n_{h}^{i} \rho_{h}(j / i)-n_{h}^{j} \rho_{h}(i / j)\right],} \\
& k \neq h \in\{s, u s\}, j \neq i \in\{A, B\} .
\end{aligned}
$$

The first two terms correspond to the flow of workers within the country and the second two represent the international flow of workers of a given type. Note that:

- $\quad$ The inflow to subpopulation $h$ of country $j$ is given by: $n_{k}^{j} w_{k}^{j} p^{j}(h / k)+n_{h}^{i} w_{h}^{i} \rho_{h}(j / i)$

- $\quad$ The outflow from subpopulation $h$ of country $j$ is given by: $n_{h}^{j} w_{h}^{j} p^{j}(k / h)+n_{h}^{j} w_{h}^{j} \rho_{h}(i / j)$

Rearranging terms, and considering that the law of large number allows us consider an aggregate random process as a deterministic one, we consider that the net flow of individuals towards each subpopulation in every period of time $t$ is summarized by the following dynamical system:

$$
\begin{aligned}
& \dot{n}_{h}^{j}=\left[n_{k}^{j} w_{k}^{j} p^{j}(h / k)-n_{h}^{j} w_{h}^{j} p^{j}(k / h)\right] \\
& +\left[n_{h}^{i} w_{h}^{i} \rho^{h}(j / i)-n_{h}^{j} w_{h}^{j} \rho^{h}(i / j)\right], \\
& j \neq i \in\{A, B\}, \text { and } h \neq k \in\{s, u s\}
\end{aligned}
$$

Where $n_{h}^{j}$ is a temporal function such that $n_{h}^{j}:[0, \infty] \rightarrow[0,1]$, and a point over each of these functions indicates its temporary modification. In other words, the derivative of $n_{h}^{j}(t)$ with respect to time, $\dot{n}_{h}^{j}(t)=\frac{d}{d t} n_{h}^{j}(t)$. In time $t$, the population state is given by the distribution of agents in the different subgroups: 
$n(t)=\left(n^{A}(t), n^{B}(t)\right) \quad$ where $\quad n^{j}(t)=\left(n_{s}^{j}(t), n_{u s}^{j}(t)\right)$

$\in \Delta, j \in\{A, B\}$. To simplify the notation, we do not write the time $t$ : Assuming the simple and particular imitation process where all reviewing workers adopt the strategy of the first peer that he/she meets, and that the workers' population is homogeneously distributed, it follows that $\rho^{j}(h / k)=n_{h}^{j}$ and $\rho_{h}(i / j)$ corresponds to the share of workers in subpopulation $h$ from country $j$, who are willing to migrate. Under these assumptions the population dynamics (10) is given by:

$\dot{n}_{h}^{j}=\left[n_{k}^{j} w_{k}^{j}-n_{k}^{j} w_{h}^{j}\right]+\left[n_{h}^{i} w_{h}^{i} \rho_{h}(j / i)-n_{h}^{j} w_{h}^{j} \rho_{h}(i / j)\right]$,

$j \neq i \in\{A, B\}$, and $h \neq k \in\{s, u s\}$.

It is natural to consider that workers with less successful strategies review their strategies at a higher rate than workers with more successful strategies. That is:

$w_{h}^{j}=\alpha-\beta E_{h}^{j}$

$\alpha, \beta \in R: 1>\alpha \geq 0, \beta>0$ and $\frac{1-\alpha}{\beta} \geq \max _{t \in\left[t_{o}, t_{f}\right]}$

$\left\{\max \left\{E_{h}^{A}(t), E_{h}^{B}(t)\right\}\right\}$.

Substituting (12) in equation (11) gives the following evolutionary dynamics:

$\dot{n}_{h}^{j}=n_{k}^{j} n_{h}^{j} \beta\left[E_{h}^{j}-E_{k}^{j}\right]+\left[n_{h}^{i} w_{h}^{i} \rho^{h}(j / i)-n_{h}^{j} w_{h}^{j} \rho^{h}(i / j)\right.$,

$j \neq k \in\{A, B\}, h \neq i \in\{s, u s\}$.

The share of workers in country $i$ wishing to migrate increases with the difference $E_{h}^{j}-E_{h}^{i}$, i.e:

$\rho^{h}(m / i)=\left\{\begin{array}{lc}a_{h}\left(E_{h}^{j}-E_{h}^{i}\right) & \text { if }\left(E_{h}^{j}-E_{h}^{i}\right)>0 . \\ 0 & \text { otherwise }\end{array}\right.$

where $a_{h}: 1 / a_{h} \geq \max _{t \in\left[t_{o}, t_{f}\right]}\left(E_{h}^{j}(t)-E_{i}^{j}(t)\right)$. Substitution of (12) in equation (13) gives the following evolutionary dynamics:

$\dot{n}_{h}^{j}=n_{k}^{j} n_{h}^{j} \beta\left[E_{k}^{j}-E_{h}^{j}\right]+$

$\left[n_{h}^{i}\left(\alpha-\beta E_{h}^{i}\right) \rho^{h}(j / i)-n_{h}^{j}\left(\alpha-\beta E_{h}^{j}\right) \rho^{h}(i / j)\right]$,

or:

$\dot{n}_{h}^{j}=n_{k}^{j} n_{h}^{j} \beta\left[E_{k}^{j}-E_{h}^{j}\right]+$

$\left[n_{h}^{i}\left(\alpha-\beta E_{h}^{i}\right)\left(E_{h}^{j}-E_{h}^{i}\right) I_{\left(E_{h}^{j}-E_{h}^{i}\right)>0}-n_{h}^{j}\left(\alpha-\beta E_{h}^{j}\right)\right]$

$\left.\left(E_{h}^{j}-E_{h}^{i}\right) I_{\left(E_{h}^{j}-E_{h}^{i}\right)<0}\right] a_{h}$, where the characteristic probability function, $I_{\left(E_{h}^{j}-E_{h}^{i}\right)}$, is de ned as:

$I_{\left(E_{h}^{j}-E_{h}^{i}\right)>0}= \begin{cases}1 & \text { if }\left(E_{h}^{j}-E_{h}^{i}\right)>0 \\ 0 & \text { otherwise. }\end{cases}$

Analogously for $I_{\left(E_{h}^{j}-E_{h}^{i}\right)<0}$. Note that, if the expected payoff of skilled workers at home country (in this case the country $B$ ) is larger than the corresponding expected payoff in a foreign country (in this case the country $A$ ), i.e,. if $E_{s}^{B} \geq E_{s}^{A}$, then the flux of these kind of workers from $B$ to $A$ is equal to zero, that is there is no migration of skilled workers from $B$ to $A$. Then by strategic complementarities (see payoff matrix (3)), the country with skilled labor shortages, will also shortage of innovative firms and will be caught in a poverty trap characterized by unskilled workers and non-innovative firms.

Assume that wages and education costs (or training costs) are fixed. Therefore we can state that:

Proposition 2. For a home country $B$ and a foreign country $A$, there exists a threshold value for which workers choose to migrate or not.

Proof. Consider that $E_{s}^{B} \geq E_{s}^{A}$, then

$p_{I}^{A}(t) Y_{I s}^{A}+p_{N I}^{A} Y_{N I s}^{A}-c_{s}^{A}>p_{I}^{B}(t) Y_{I s}^{A}+p_{N I}^{B} Y_{N I s}^{B}-c_{s}^{B}$,

since, wages and education costs are fixed, this condition can be expressed by the inequality:

$p_{I}^{A}(t)>\frac{Y_{I s}^{A}-Y_{N I s}^{B}}{Y_{I s}^{A}-Y_{N I s}^{A}} p_{I}^{B}(t)+\frac{\left(Y_{N I s}^{A}+Y_{N I s}^{B}\right)+\left(c_{s}^{A}-c_{s}^{B}\right)}{Y_{I s}^{A}-Y_{N I s}^{A}}$.

The threshold value is such that:

$P_{I}^{A T}(t)=\frac{Y_{I s}^{A}-Y_{N I s}^{B}}{Y_{I s}^{A}-Y_{N I s}^{A}} p_{I}^{B}(t)+\frac{\left(Y_{N I s}^{A}+Y_{N I s}^{B}\right)+\left(c_{s}^{A}-c_{s}^{B}\right)}{Y_{I s}^{A}-Y_{N I s}^{A}}$,

if in time, $t, P_{I}^{A}(t)>P_{I}^{A T}(t)$, then the flow of migration from country $B$ to country $A$ is equal to zero.

Note that this threshold depends on the parameters of the economies along a line, se Figure 1, whose slope is given by the tangent of the angle $\alpha$

$\tan \alpha=\frac{Y_{I s}^{A}-Y_{N I s}^{B}}{Y_{I s}^{A}-Y_{N I s}^{A}}$ and $\eta_{0}=\frac{\left(Y_{N I s}^{A}+Y_{N I s}^{B}\right)+\left(c_{s}^{A}-c_{s}^{B}\right)}{Y_{I s}^{A}-Y_{N I s}^{A}}$

This line separates the space into two regions, such that if the number of innovative firms in country $A$ is 


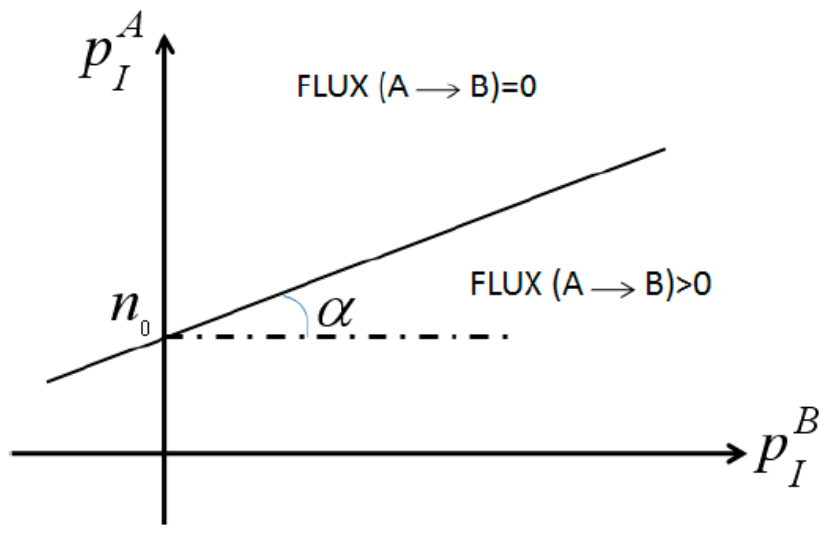

Figure 1: The threshold value, a geometric interpretation.

above the line, the skilled workers migrate from country $A$ to country $B$. The opposite happening if this value is below the straight.

As we already noted the migration of skilled workers from country $B$ to country $A$ raises the productivity of country $A$, however if the number of immigrants continues to increase, migration can become a negative externality. Analyzing equation (17) we can conclude that migrant regulation can be of help to avoid this negative facts.

\section{CONCLUDING REMARKS}

In this paper was argued that the strategic foundations of the migrant behavior are based in the imitation of the peers. Our results indicate that the economic effects of migration vary widely. Sending countries may experience both gains (a high-level equilibrium) and losses (a poverty trap) in the shortterm, and then mantaining in the long-term such a given situation. For host countries, the temporary programs can help to address skills shortages but can decrease domestic wages, however the migration of skilled workers have a strong and immediate effects on the welfare of both the sender and the receiving countries only in the presence of $R \& D$ complementarities.

The migration has an important impact in economic development and in the social welfare of both countries, in the home one and in the foreign country. The migratory flouw can be encouraged or discouraged by means of the implementation of different social an economic policies. Subsides for education or for technological innovation can give place to an increasing flow of skilled workers to the country in which this policy is developed more intensively.
We show that only if the number of innovative firms in a home country surpass a fixed threshold value, then the migration of skilled workers is null and moreover, if this value is overtaken, a positive process of imitation of workers to acquire skills takes place in the home country.

Even that the migration of skilled workers from country $B$ to country $A$ raises the productivity of the latter, it could be a negative externality if there is no complementarity with an increasing percentage of innovative firms. This fact must be taken account by a benevolent planner interested in the fact that skilled workers may arrive to the country. Under particular economic conditions, to obtain good economic results from a migratory process, is necessary to design an appropriate policy of incentives for innovative firms. Skilled workers and innovative firms are complementary terms for economic development.

On the other hand, it is necessary to take into account that, the emigration of skilled workers plays a negative role in the welfare of the home country. The low number of skilled workers makes that such a country looses in competitiveness. The main tools of economic policy to encourage or discourage the migration of skilled workers, are to promote education of workers and the promotion of R\&D activities or innovation among firms.

\section{ACKNOWLEDGEMENTS}

We are grateful to two anonymous referees for many helpful suggestions and constructive comments. We thank seminar participants at DGS II 2013 International Conference and Advanced School Planet Earth, Dynamics, Games and Science II, Portugal, 28 August to 6 September 2013. We also thank the financial support from CONACYT Mexico.

\section{REFERENCES}

Accinelli, E. and Carrera, E.S. (2011), "Strategic complementarities between innovative firms and skilled workers: the poverty trap and the policymaker's intervention", Structural Change and Economic Dynamics, 22(1), 30-40. http://dx.doi.org/10.1016/i.strueco.2010.11.004

Bauer, T. G., Epstein and I. N. Gang, (2002), "Herd Effects or Migration Networks? The Location Choice of Mexican Immigrants in the U.S.", IZA Discussion Paper, N. 551

Bauer, T. and K. F. Zimmermann, (1997), "Network Migration of Ethnic Germans", International Migration Review 1(1), pp. 143-149.

http://dx.doi.org/10.2307/2547262

Bertrand M.; E. Luttmer and S. Mullainathan (2000), "Network Effects and Network Cultures" Quarterly Journal of Economics 115, pp. 1019-1055.

http://dx.doi.org/10.1162/003355300554971 
Borges et al. Bo Borges, Bernhard; Goldstein, Daniel G.; Ortmann, Andreas; Gigerenzer, Gerd Gigerenzer, Gerd Todd, Peter M. Can ignorance beat the stock market?. Evolution and cognition., (pp. 59-72). New York, NY, US: Oxford University Press, The ABC Research Groupxv. (1999).

Borjas, G. J. (1990), Friends or Strangers: The Impact of Immigrants on the US Economy, Basic Books 41.

Borjas, G. J. (1994), "The Economics of Immigration", The Journal of Economic Literature 32(4), pp. 1667-1717.

Boyd, M. (1989), "Family and Personal Networks in International Migration: Recent Developments and New Agendas", International Migration Review 23(3), Special Silver Anniversary Issue: International Migration In Assessment for the 90 's, pp. 638-670.

Carlsson, S. (1979), "Chronology and composition of Swedish emigration to America", in Runblom, Harald, and Hans Norman (eds.) (1976). From Sweden to America: A History of the Migration. Minneapolis: University of Minnesota Press.

Carrera, E. J. S. (2009), "The Evolutionary Game of Poverty Trapsâ€ , Quaderni Del Dipartimento di Economia Politica Universita' degli Studi di Siena, no. 555.

Coniglio, N. D. (2003), "Migropolis: Migration Networks and Formation of Ethnic Clusters in Cities", SNF Working Paper, 46/03.

Cressman, R., Morrison, W. G. and J. F. Wen (1998), "On the Evolutionary Dynamics of Crime", The Canadian Journal of Economics vol. 31(5), pp. 1101-1117. http://dx.doi.org/10.2307/136461

Duflo. E. and Saez E. (2003), "The Role of Information and Social Interactions in Retirement Plan Decisions: Evidence From a Randomized Experiment", Quarterly Journal of Economics 118, pp. 815-842.

Durlauf, S. (2004), Neighborhood effects, In: Handbook of Regional and Urban Economics Vol. 4, J.V. Henderson and J-F. Thisse (Eds.), Amsterdam: Elsevier Science, pp. 2173-2242.

Friedman, D. (1998), "On Economic Applications of Evolutionary Game Theory", Journal of Evolutionary Economics, vol. 8, pp. 15-43. http://dx.doi.org/10.1007/s001910050054

Glaeser, E.; B. Sacerdote and J.A. Scheinkman (1999), "Crime and Social Interactions", Quarterly Journal of Economics 111, pp. 507-548. http://dx.doi.org/10.2307/2946686

Graham B. S. (2008), "Identifying Social Interactions through Excess Variance Contrasts", Econometrica 76(3), pp. 643-660. http://dx.doi.org/10.1111/j.1468-0262.2008.00850.x

Gigerenzer, G.; Gaissmaier, W. (2011) GG Heuristic decision making. Annual Review of Psicology, 62, 451-482.

Gigerenzer, G.; Goldstein, D.G (2011) Getall The recognition heuristic: A decade of research. Judement and decision Making 6, 100-121.

Hart, R. A. (1975), "Interregional Economic Migration: Some Theoretical Considerations", Journal of Regional Science 15(2), pp. 127-138.

http://dx.doi.org/10.1111/j.1467-9787.1975.tb00915.x
Heitmueller, A. (2003), "Coordination Failures in Network Migration", IZA (Institute for the Study of Labor) Discussion Papers 770 43

Hofbauer, J. and K. Sigmund (2003), "Evolutionary game dynamics", Bulletin of the American Mathematical Society (New Series) 40, pp. 479-519. http://dx.doi.org/10.1090/S0273-0979-03-00988-1

Kroft (2008), "Takeup, Social Multipliers and Optimal Social Insurance", Journal of Public Economics 92, pp. 722-737. http://dx.doi.org/10.1016/j.jpubeco.2007.06.011

Ljungmark, L. (1979), Swedish exodus. Southern Illinois University Press.

Ljungmark, L. (1992), The push- and pull-factors behind the Swedish emigration to America, Canada and Australia. In Emmer.P.C and Magnus Mörner. European Expansion and Migration. BergPublischers, Inc.

Langley, P.C. (1974), "The Spatial Allocation of Migrants in England and Wales", Scottish Journal of Political Economy (21)3. pp. 259-77. http://dx.doi.org/10.1111/j.1467-9485.1974.tb00196.x

Marmefelt, T. (2004), "Institutional Endowments and the Lithuanian Holdings as Innovative Network: A Problem of Institutional Compatibility in the Baltic Sea Area, The Review of Austrian Economics, vol. 17(1), pp. 87-113. http://dx.doi.org/10.1023/B:RAEC.0000011338.64055.20

Moretti, E. (1999), "Social Networks and Migrations: Italy 18761913", International Migration Review 33 (3), pp. 640-657. http://dx.doi.org/10.2307/2547529

Munshi, K., (2001), "Identification of Network Effects: Mexican Migrants in the U.S. Labor Market", paper presented at NEUDC conference, Boston, MA.

Munshi K., (2003), "Networks in the Modern Economy: Mexican Migrants in the U.S. Labour Market", Quarterly Journal of Economics 118 (2), pp. 549-599. http://dx.doi.org/10.1162/003355303321675455

Sandholm, W. H. (2010), Population Games and Evolutionary Dynamics. MIT Press, Cambridge.

SCB: Statistiska Centralbyrn (1969). Historisk statistik fr Sverige. Allmnna Frlaget.

Todaro, M. P.(1969), "A Model of Labor Migration and Urban Unemployement in Less Developed Countries", American Economic Review 69, pp. 486-499.

Todaro, M. P. and J. Harris (1970), "Migration Unemployement and Developement: A Two Sectors Analysis", American Economic Review 60 (1), pp.126-42.

Weibull, J. (1995), Evolutionary Game Theory, The Mit Press.

Winters, P.; A. de Janvry and E. Sadoulet, (2001), "Family and Community Networks in Mexico-U.S. Migration", The Journal of Human Resourches 36(1), pp. 159-184. http://dx.doi.org/10.2307/3069674

Wübben, W.; Wangeheim, F.V. (2008) WW Instant customer base analysis: Manegerial heuristics often "get a ride." Journal of Marketing 72(3) 82-93.

Received on 19-11-2013

Accepted on 21-01-2014

Published on 05-03-2014

\section{DOl: http://dx.doi.org/10.6000/1929-7092.2014.03.03}

(c) 2014 Accinelli et al.; Licensee Lifescience Global.

This is an open access article licensed under the terms of the Creative Commons Attribution Non-Commercial License (http://creativecommons.org/licenses/by-nc/3.0/) which permits unrestricted, non-commercial use, distribution and reproduction in any medium, provided the work is properly cited. 